\title{
Gravity changes observed between 2004 and 2009 near the Tokai slow-slip area and prospects for detecting fluid flow during future slow-slip events
}

\author{
Yoshiyuki Tanaka ${ }^{1}$, Aitaro Kato ${ }^{1}$, Takayuki Sugano ${ }^{1}$, Guangyu $\mathrm{Fu}^{2}$, Xinlin Zhang ${ }^{1}$, Masato Furuya ${ }^{3}$, \\ Wenke Sun ${ }^{4}$, Shuhei Okubo ${ }^{1}$, Shigeo Matsumoto ${ }^{5}$, Masaki Honda ${ }^{6}$, Yasuhiro Sugawara ${ }^{6}$, \\ Isao $\mathrm{Ueda}^{6}$, Masaaki Kusaka ${ }^{6}$, and Misao Ishihara ${ }^{6}$ \\ ${ }^{1}$ Earthquake Research Institute, University of Tokyo, 1-1-1 Yayoi, Bunkyo-ku, Tokyo 113-0032, Japan \\ ${ }^{2}$ Institute of Earthquake Science, China Earthquake Administration, Beijing 100036, China \\ ${ }^{3}$ Department of Natural History Sciences, Graduate School of Science, Hokkaido University, N10W8, Kita-ku, Sapporo 060-0810 Japan \\ ${ }^{4}$ College of Earth Science, Graduate University of Chinese Academy of Sciences, 19A Yuquanlu, Beijing, 100049, China \\ ${ }^{5}$ Drilling Technology Department, Sumiko Consultants Co., Ltd., 9-7, Ikenohata 2-Chome, Taito-Ku, Tokyo 110-0008, Japan \\ ${ }^{6}$ Department of Geodesy, Geospatial Information Authority of Japan, 1 Kitasato, Tsukuba, Ibaraki 305-0811, Japan
}

(Received July 8, 2010; Revised October 15, 2010; Accepted November 10, 2010; Online published February 3, 2011)

\begin{abstract}
Slow-slip events (SSEs) have been observed in many plate-boundary zones along the circum-Paci c seismic belt. Previous studies have revealed that high-pressure uids supplied from the subducted oceanic plate can generate SSEs. However, the behavior of these uids during an SSE has not been fully elucidated. This paper discusses possible uid migration along the plate boundary on the basis of spatiotemporal gravity changes observed by absolute and relative gravimeters during a long-term SSE in the Tokai district, Japan. Relativegravity data are sometimes unreliable because of limited observation accuracies and possible noise produced by groundwater. Nevertheless, the observed gravity changes show a systematic pattern of spatial changes over the slow-slip area. This pattern can be explained by a poroelastic model assuming uid migration along the plate interface, for which an inversion indicates a permeability of about $10^{-15} \mathrm{~m}^{2}$. This lies within the range of permeability values inferred by other studies in slow-slip areas. Long-term SSEs have occurred repeatedly in the Tokai district. If the permeability remains greater than $10^{-15} \mathrm{~m}^{2}$ during a future SSE, it will be possible to detect uid migration by improving the observation accuracy to the $1-\mu \mathrm{Gal}$ level and accurately evaluating groundwater-related noise.
\end{abstract}

Key words: Slow earthquake, slow slip, gravity, uid, poroelasticity, permeability, subduction zone, crustal deformation.

\section{Introduction}

Slow-slip events (SSEs) in plate-subduction zones are related to the presence of high-pressure pore uids that are generated by the dehydration of hydrous minerals within the subducted oceanic plate (Schwartz and Rokosky, 2007; Audet et al., 2009; Song et al., 2009; Kato et al., 2010). Geodetic and seismological observations have revealed that a majority of SSEs occur repeatedly on the plate boundary at depths of around 20-40 km (Schwartz and Rokosky, 2007; Delahaye et al., 2009), just beneath the seismogenic zone for megathrust earthquakes. Seismic studies have detected high-Poisson-ratio anomalies that indicate the presence of pore uids in the source areas of these events (Audet et al., 2009; Kato et al., 2010). Deep non-volcanic tremors have also been detected in some of these areas, and their rapid migrations can be explained by uid ow along the subducting plate (Vidale et al., 2009). Moreover, the fact that tremors can apparently be triggered by very small stress perturbations suggests that the shear strength is small on the

Copyright (C) The Society of Geomagnetism and Earth, Planetary and Space Sciences (SGEPSS); The Seismological Society of Japan; The Volcanological Society of Japan; The Geodetic Society of Japan; The Japanese Society for Planetary Sciences; TERRAPUB.

doi:10.5047/eps.2010.11.003 plate interface because of high-pressured uids (Miyazawa and Mori, 2006). Laboratory experiments on rock friction have indicated that the injection of pore uids effectively decreases shear strength (Kato et al., 2003). Simulations incorporating these experimental results imply that high-pressure pore uids help to create a frictional regime on plate boundaries that could periodically trigger SSEs (Scholz, 1998; Liu and Rice, 2007).

While laboratory and numerical experiments suggest that high-pressure uids can induce SSEs, little is known about the way uids and shear-rupture processes interact on scales relevant to the natural environment.

Recently, terrestrial and satellite measurements have detected minute gravity changes, on the order of $1 \mu \mathrm{Gal}=$ $10 \mathrm{~nm} / \mathrm{s}^{2}$, caused by earthquake-induced crustal deformation (Tanaka et al., 2001; Imanishi et al., 2004; Chen et al., 2007). There have also been reports of gravity changes induced by uid ow within the crust, such as magma migration due to volcanic activities (Battaglia et al., 1999; Furuya et al., 2003), groundwater ow (Kazama and Okubo, 2009) and post-seismic mantle-water ow (Ogawa and Heki, 2007). Absolute gravity measurements in the Cascadia plate-subduction zone suggest a long-term increase in the mass anomaly of unknown origin (Mazzotti et 

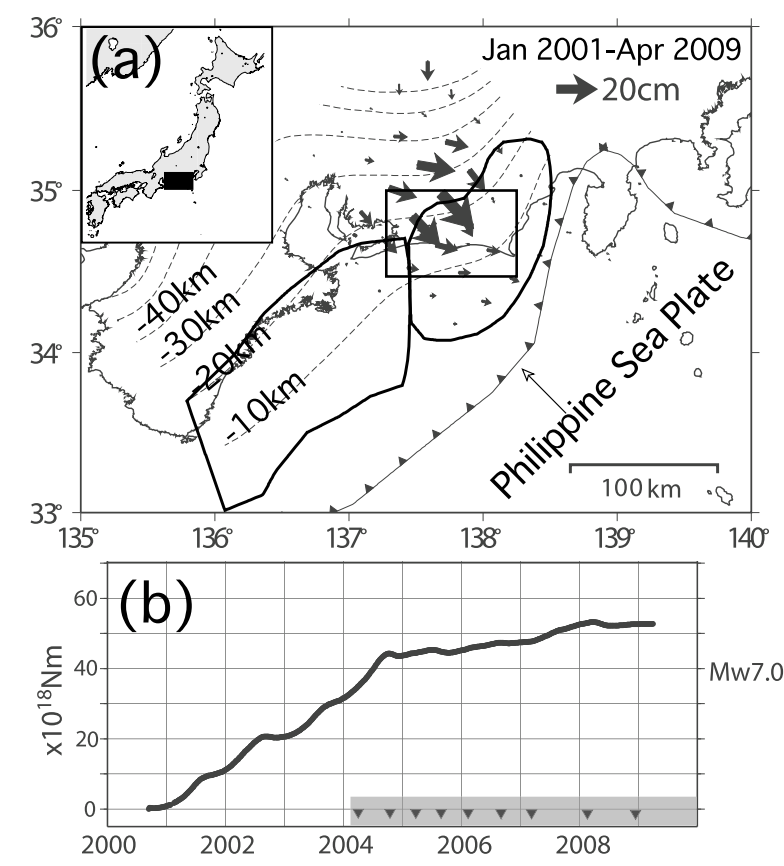

Fig. 1. (a) Map of the Tokai area. The Philippine Sea Plate is subducting in the NW direction beneath the Eurasian Plate. Dashed lines show depth contours of the plate interface (Noguchi, 1996; Nakamura et al., 1997). The vectors represent the total amount of slip that took place on the interface by 2009 . The hypothetical source area of the anticipated Tokai earthquake is delineated by thick curves near the center (Central Disaster Management Council, 2001). (b) The accumulated seismic-moment release. The inverted triangles represent the times that gravity measurements took place in and around the Tokai slow-slip area.

al., 2007). Absolute and relative gravity measurements are also being performed on the island of Taiwan to investigate tectonic deformation and mass-transfer effects (Mouyen et al., 2009). A more precise observation method combining absolute and superconducting gravimeters has been developed to monitor slow vertical deformation (Van Camp et al., 2005). This article reports on gravity changes observed during a long-term SSE and discusses whether these changes can be explained by subsurface density changes caused by high-pressure-fluid flow along the plate interface.

\section{Observations}

\subsection{Overview}

A long-term SSE began to take place in the Tokai area of Japan in 2000 (Miyazaki et al., 2006). Figure 1(a) shows the slip vectors on the plate interface inferred from surfacedisplacement data obtained by GEONET, a continuous GPS observation network (Geospatial Information Authority of Japan, 2009a). The slip continued to accumulate until April 2009 , amounting to about $20 \mathrm{~cm}$ at depths of around $25 \mathrm{~km}$. The accumulated seismic-moment release, demonstrated in Fig. 1(b), also indicates that the event continued until 2009. The distribution of slip rates is shown in Fig. 2.

Gravity measurements have been conducted in the slowslip area at a rate of once or twice every year after the reference site A2 was set up in 2004 (Fig. 2). Gravity observations have also been in operation near the tip of the peninsula since 1996. Gravity values at A1 and A2 were determined with an accuracy of $2 \mu \mathrm{Gal}$ using FG5 absolute

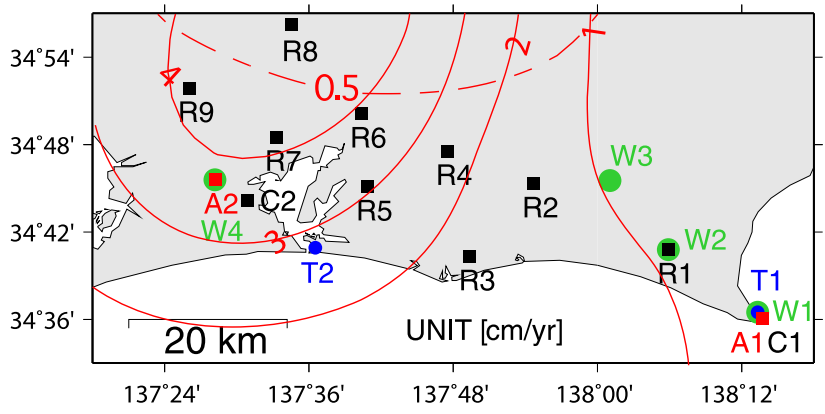

Fig. 2. Locations of the observation sites. Red squares (A1 and A2), absolute gravity measurement sites. The records at A1 and A2 were corrected for vertical crustal movement using GPS data at stations C1 and $\mathrm{C} 2$, respectively. Black squares (R1-R9), relative gravity measurement sites. Measurements were conducted on leveling markers that are attached to the foundation of GPS station equipment. T1 and T2, tidal stations. W1-W4, observation wells for monitoring groundwater levels. Solid and dashed contours, slip rates on the plate boundary for 2001-2005 and 2006-2009, respectively (cm/yr). These rates were determined with the same data that were used to calculate the slip distribution in Fig. 1.

gravimeters (Okubo et al., 1997). Differences in gravity at these reference sites and at control stations of the GPS network (R1-R9) were measured with an accuracy of approximately $10 \mu \mathrm{Gal}$ using calibrated LaCoste and Romberg (L\&R) Model G relative gravimeters (Torge, 1989). The relative measurements were performed using two of the three available gravimeters (denoted S/N 581, 705, and 876) during each campaign with a view to eliminating instrumental differences. Combining robust absolute gravity measurements with less robust but easier relative measurements using portable L\&R gravimeters helped to enhance the spatial resolution of the long-term gravity change estimates. The same approach was previously adopted to detect co-seismic and magma-migration-induced gravity changes (Tanaka et al., 2001; Furuya et al., 2003).

\subsection{Absolute gravity data}

During each campaign, absolute gravity measurements were performed at crustal-deformation observation facilities with 100 drops per set, intervals of 30 min between measurement sets, and a total duration of approximately $48 \mathrm{~h}$. Corrections were applied to the raw data with a view to isolating long-term trends in gravity due to subsurface mass redistribution induced by the SSE. The effects of solid-Earth tides and atmospheric pressure variations were eliminated using software attached to the FG5 gravimeter. Oceanic tides were corrected for by the method of Matsumoto et al. (2001). Gravity changes attributable to vertical movement of the observation sites were subtracted using daily GPS coordinate data at the nearest GEONET stations (IDs 93101 and 93104). Their locations are shown in Fig. 2 ( $\mathrm{C} 1$ for $\mathrm{A} 1$ and $\mathrm{C} 2$ for $\mathrm{A} 2$ ). To avoid correcting the gravity records for spurious annual and semi-annual variations in GPS data, such as those due to atmospheric delay, coordinate data were smoothed by polynomial fitting before being used in the ordinary Bouguer correction. An average crustal density of $2.67 \mathrm{~g} / \mathrm{cm}^{3}$ was assumed for all sites. Spatial variations in the crustal density can be ignored in the following discussions because their potential 


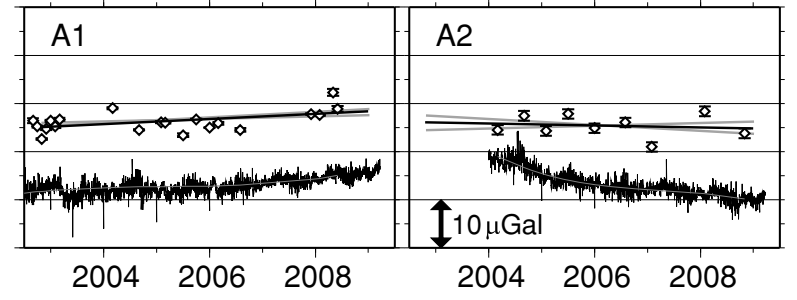

Fig. 3. Time series of the observed gravity changes at the absolute gravity measurement sites with corrections applied as described in the text. The error bars denote scatters among different measurement sets. One division of the vertical axis corresponds to $10 \mu \mathrm{Gal}$. The linear trends and their prediction bands are superimposed upon the data points (solid black and gray lines). The effects of vertical movement of the sites have been eliminated from the gravity changes. Corrections derived from daily vertical GPS coordinate data are shown in thin and ragged black curves, and smoothed into polynomial functions, indicated by red curves.

contributions are more than one order of magnitude smaller than the standard deviations of the gravity trends estimated for the observed changes. Figure 3 displays the time-series gravity data after these corrections were applied. The effects of the crustal movement used in the corrections are also shown. The linear trends estimated by a least-squares method were $0.5 \pm 0.2$ and $-0.2 \pm 0.56 \mu \mathrm{Gal} / \mathrm{yr}$ at $\mathrm{A} 1$ and A2, respectively, and are also shown in Fig. 3.

At A1, there seemed to be a gravity change between 1996 and 2000 that could not be attributed to the vertical movement of the site (Geospatial Information Authority of Japan, 2009b). However, no clear change was discerned around the time the SSE started in the fall of 2000. In the following, we focus on gravity changes that took place during the SSE and do not discuss changes prior to the SSE.

\subsection{Relative gravity data}

The relative gravimeters were calibrated as follows. The scale factors were determined from single-day observations in Miyazaki, Hokkaido, and Tokyo and at Mt. Fuji, Japan, where reference gravity values had been determined precisely by absolute gravity measurements. The effect of magnetic orientation was measured in a laboratory at the Earthquake Research Institute (ERI). Periodic errors due to dial turns were corrected for by using data measured in an ERI building and all available data from previous observations. An automated Burris gravimeter equipped with a digital feedback system was used to correct for dial rotations worth less than ten turns. These errors remained smaller than $10 \mu \mathrm{Gal}$.

Observations in the Tokai area were conducted following a conventional procedure in which all measurements were repeated twice within a single day to evaluate drift errors. The precision of each gravity measurement was calculated using a least-squares method incorporating a model of solid-Earth tides to remove linear drifts. At this stage, data with measurement precisions poorer than approximately $10 \mu \mathrm{Gal}$ were rejected because they were considered to contain human-induced measurement errors. Oceanic tides and vertical crustal movements at the measurement sites were corrected for by following the same method used for the absolute gravity data. The GPS stations used for these corrections are listed in column (d) in Table 1. Air pressure

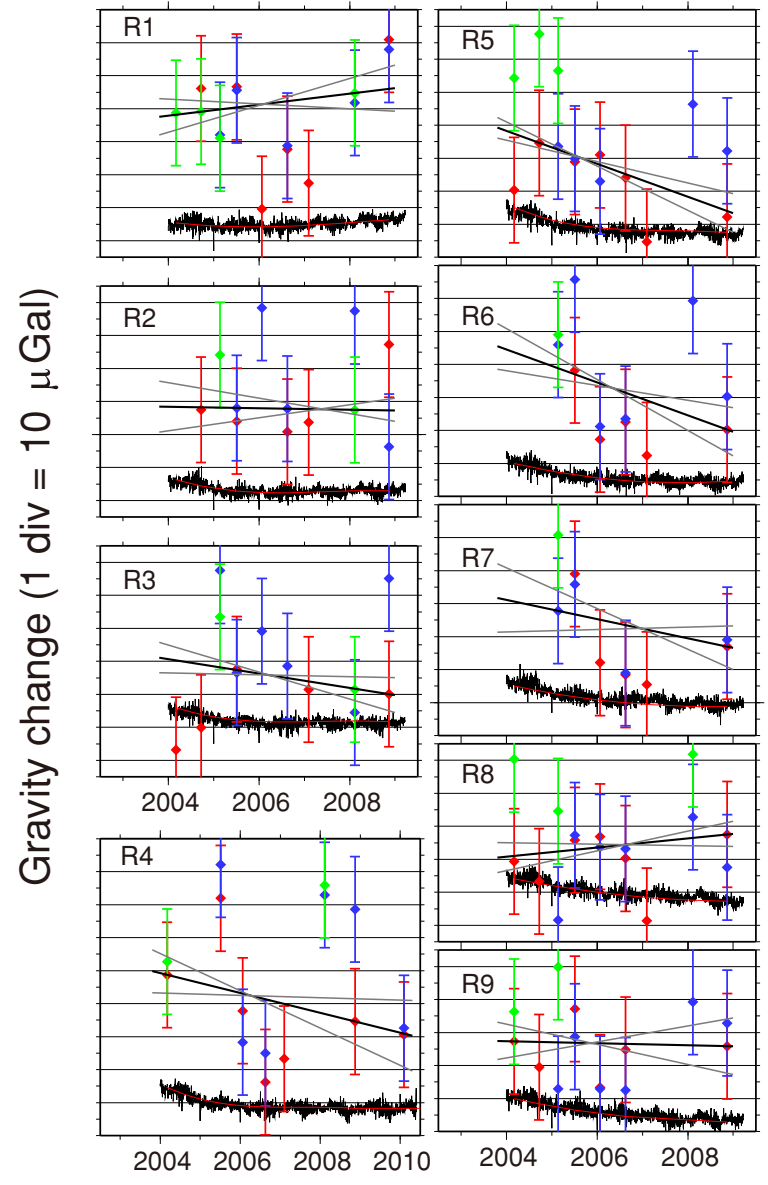

Fig. 4. Time series of the observed gravity changes at the relative gravity measurement sites with corrections applied as described in the text. The red, blue, and green points denote gravity changes observed by the relative gravimeters $\mathrm{S} / \mathrm{N} \mathrm{581,} 705$ and 876, respectively. The errors for these data were evaluated by a statistical analysis $( \pm 16 \mu \mathrm{Gal}$; see Section 2.3). In all panels, one division of the vertical axis corresponds to $10 \mu \mathrm{Gal}$. The black and gray solid lines denote the observed linear trends and their prediction bands. The linear trends were estimated using the minimum L1-norm condition (see also Table 1). At R4, gravity data obtained during different observation periods demonstrate larger scatters than elsewhere. Measurement data from 2010 have been incorporated in the analysis to enhance the accuracy of trend estimation.

was corrected for by using in-situ data obtained during each measurement.

The resulting time-series gravity data are displayed in Fig. 4. Errors in these data were evaluated statistically using records obtained simultaneously by a pair of gravimeters. Figure 5(a) shows the histogram of differences in gravity records obtained by the gravimeter pair S/N 581 and 705 . The differences follow a Laplace distribution rather than a Gaussian distribution (see section 8 of Menke, 1989). For the Laplace distribution, the mean and standard deviation were -1.7 and $13 \mu \mathrm{Gal}$, respectively. The systematic difference of $1.7 \mu \mathrm{Gal}$ is negligible compared to the deviation of $13 \mu \mathrm{Gal}$. For the two other gravimeter pairs, the numbers of simultaneous-measurement records were not large enough to identify what probability density distribution they followed. We therefore fit probability density functions to all data from the three pairs combined. The Laplace distribution again presented a better fit than the Gaussian distribution (Fig. 5(b)). The mean and standard deviation 
Table 1. Trend estimates by absolute and relative gravity data.

\begin{tabular}{ccccc}
\hline (a) Code & (b) Lon. & (c) Lat. (deg.) & (d) GPS site & (e) Trend \& $\sigma(\mu \mathrm{Gal} / \mathrm{yr})$ \\
\hline A1 & 138.2289 & 34.6006 & 93031 & $+0.5 \pm 0.2$ \\
A2 & 137.4700 & 34.7600 & 93104 & $-0.2 \pm 0.56$ \\
R1 & 138.0983 & 34.6799 & H13 & $+1.7 \pm 1.4$ \\
R2 & 137.9113 & 34.7554 & 93096 & $-0.2 \pm 2.2$ \\
R3 & 137.8234 & 34.6719 & 93098 & $-2.2 \pm 1.9$ \\
R4 & 137.7918 & 34.7928 & 93097 & $-2.9 \pm 2.6$ \\
R5 & 137.6808 & 34.7520 & 970821 & $-5.0 \pm 1.7$ \\
R6 & 137.6723 & 34.8353 & 93050 & $-5.0 \pm 2.7$ \\
R7 & 137.5543 & 34.8087 & 93103 & $-2.9 \pm 3.3$ \\
R8 & 137.5755 & 34.9377 & 93099 & $+1.4 \pm 1.6$ \\
R9 & 137.4340 & 34.8648 & 93102 & $-0.3 \pm 2.7$ \\
\hline
\end{tabular}
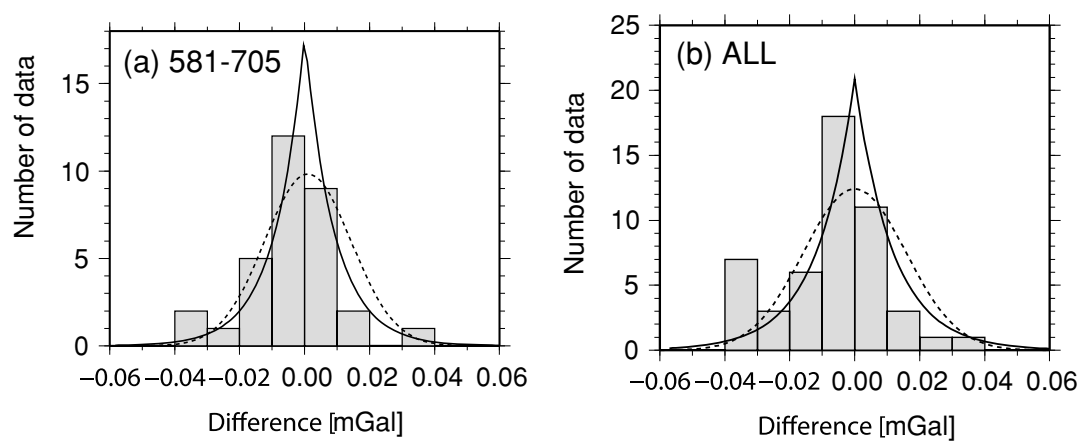

Fig. 5. (a) Histogram of differences in gravity obtained by relative gravimeters S/N 581 and 705 . The differences correspond to those between red and blue data points in Fig. 4 that were obtained simultaneously. The solid and dotted curves denote the fit of two types of probability density functions (Laplace and Gaussian distributions). The variances for the fitting were 5.8 for the former and 30.9 for the latter. (b) The same as for (a) but for all three gravimeter pairs (581-705, 705-876 and 581-876). The variances for the fitting were 38 and 119 for the Laplace and the Gaussian distributions, respectively.

were -3.0 and $16 \mu \mathrm{Gal}$, respectively. From these results, we estimated the measurement accuracy of relative gravity changes to be $\pm 16 \mu \mathrm{Gal}$ and assumed that there were no significant systematic offsets between different portions of data obtained by different instrumentations. The estimated accuracy is denoted by error bars in Fig. 4.

On the basis of the above analysis, trends in the timeseries data were determined using the minimum L1-norm condition (Menke, 1989). All data were assigned an equal weight of $1 / \sigma^{2}=1 /(16 \mu \mathrm{Gal})^{2}$. The result is shown in Table 1 and Fig. 4 with prediction bands corresponding to $1 \sigma$.

\subsection{Other potential sources of gravity change}

We did not correct the absolute and relative gravity data for changes arising from the following sources because their effects were estimated to be smaller than the measurement accuracy.

2.4.1 Variations in sea-surface height We have evaluated long-term gravity changes due to variations in sea-surface height for sites A1 and R3, which are located only a few hundred meters from the coastline, using local tide-gauge data (available on the Web site of the Coastal Movements Data Center, Geospatial Information Authority of Japan, http://cais.gsi.go.jp/cmdc/center/annualgra.html). The linear trends in sea-surface height at tide stations T1 and T2 (Fig. 2) between 2004 and 2009 were $-5.6 \pm 4.7$ and $-9.2 \pm 5.1 \mathrm{~mm} / \mathrm{yr}$, respectively, with vertical crustal movements removed by the method of Kato and Tsumura (1979)
(Geospatial Information Authority of Japan, 2009c). These are expected to have effects of approximately only 0.01 and $0.1 \mu \mathrm{Gal} / \mathrm{yr}$ at A1 and R3, respectively.

We have also evaluated gravity changes due to the fluctuation of the Kuroshio axis using data published by the Hydrographic and Oceanographic Department of the Japan Coast Guard (http://www1.kaiho.mlit.go.jp/ KANKYO/KAIYO/qboc/index.html; in Japanese). Its effect was estimated to be less than $0.01 \mu \mathrm{Gal}$ for site A1.

2.4.2 Variations in groundwater levels A number of groundwater observation wells, operated by the Geological Survey of Japan to monitor crustal deformation (depths 150-340 m), are located near gravity measurement stations A1, R1, and A2. Their locations are marked as W1W4 in Fig. 2. Time-series groundwater level data from these wells are illustrated in Reports of the Coordinating Committee for Earthquake Prediction (Geological Survey of Japan, 2002, 2003, 2004, 2006, 2009, 2010) (http://cais.gsi.go.jp/YOCHIREN/report.e.html). Annual variations dominate in all these data sets. At W1, the annual variation was approximately $20 \mathrm{~cm}$ peak-to-peak. A secular increase of $10 \mathrm{~cm}$ took place between January 2005 and January 2007, but otherwise, no clear secular variation was discerned. When a porosity of $10 \%$ is assumed (Torge, 1989), an increase of $10 \mathrm{~cm}$ is expected to bring about a gravity change of $+0.4 \mu \mathrm{Gal}(+1 \mathrm{~m}$ of water height $=$ $+40 \mu \mathrm{Gal})$, which could not have significantly affected the long-term gravity change observed at A1. At W2 and W3, 
annual variations were less than $20 \mathrm{~cm}$, and no signi cant secular variations were observed. At W3, a shallower well, with a depth of $35 \mathrm{~m}$, was attached to the deep well. The shallower well had an annual variation of $40 \mathrm{~cm}$, although no obvious secular variation was discerned. This annual variation corresponds to a gravity change of $\pm 0.8 \mu \mathrm{Gal}$, which should be negligible compared to the accuracy of the relative gravity measurements at $\mathrm{R} 1$. At $\mathrm{W} 4$, the amplitude of the annual variation was approximately $50 \mathrm{~cm}$. A secular increase of $50 \mathrm{~cm}$ took place between January 2004 and September 2004, but otherwise, no remarkable trend was seen. The annual variation corresponds to a gravity change of $\pm 1 \mu \mathrm{Gal}$. This amplitude is comparable to that of the seasonal changes that can be discerned in the gravity records at A2 (Fig. 3). However, the gravity records demonstrate no obvious change that could be associated with the secular increase between January 2004 and September 2004. To evaluate the effect of groundwater more accurately, it would be necessary to conduct continuous measurements of near-surface groundwater levels and gravity and determine the admittance between these two quantities.

The effects of groundwater remain unknown for the other gravity measurement sites. Relative gravity data indicate that gravity decreased by $10-20 \mu \mathrm{Gal}$ during a 5-year period at stations R3-R7. To account for these changes by groundwater alone, changes of $2.5-5 \mathrm{~m}$ would be required at all these stations if a porosity of $10 \%$ is assumed. Such a broad variation was never observed in the shallower well at $\mathrm{W} 3$, neither in the secular nor in the seasonal component.

To develop a method to correct for gravity changes due to groundwater disturbances, continuous observations were carried out, using a superconducting gravimeter, at the National Astronomical Observatory of Japan, Mizusawa, which is located on at terrain. Secular and seasonal variations in gravity were at most several $\mu \mathrm{Gal}$ (Kazama, 2010). On the other hand, it is known that gravity changes due to groundwater sometimes amount to $20 \mu \mathrm{Gal}$ near an active volcano in Japan (Kazama and Okubo, 2009). Elevations at the gravity measurement sites in the Tokai area ranged between 6 and $110 \mathrm{~m}$, indicating that the terrain apparently has more in common with the former case than with the latter case.

2.4.3 Volumetric changes in the crust due to the slow slip event We used the dislocation theory of Okubo (1992) to evaluate the effects of elastic volumetric changes in the crust due to the SSE. The computed gravity changes, however, were at least one order of magnitude smaller than the corrections for vertical movement shown in Figs. 3 and 4. This result indicates that the effects of near-surface groundwater and pore- uid ow driven by elastic deformation (e.g. Jónsson et al., 2003) would be too small to explain the observed trends because changes in uid density are at most of the same order of magnitude as the elastic volumetric changes. The gravity changes estimated by the model of Ogawa and Heki (2007), which is based on elastic deformation, also turned out to be too small. Both of these elastic deformation models failed to explain the observed gravity changes because the moment magnitude of the $\operatorname{SSE}\left(M_{\mathrm{w}} \sim 7\right)$ was smaller and/or because the source depth $(\sim 25 \mathrm{~km})$ was larger than those in previously studied cases.

\subsection{Spatial pattern of the trends}

Although the gravity trends estimated at the relative measurement sites had large standard deviations, they demonstrated the following systematic features of spatial distribution: (1) the gravity decreased on the shallower side of the areas of maximum slow slip (R3-R7); (2) the gravity did not decrease at R2 located to the southeast and, in contrast, increased at R1 and A1 farther to the southeast; (3) no signi cant changes were observed at R8, A2, and R9 located to the north and west. Such a systematic correlation of the observed gravity changes with the slow-slip area suggests that the gravity changes may be related to the SSE, although the possibility that this pattern was generated by chance by short-term or long-term groundwater disturbances cannot be ruled out.

\section{Model}

\subsection{Mechanism driving high-pressure-fluid flow}

We have seen that mass redistribution due to uid ow driven by ordinary poroelastic deformation mechanisms is insuf cient to account for the observed gravity changes. We therefore hypothesize that a larger mass redistribution took place due to the creation of new ow paths - that is, because the permeability structure in and around the slowslip area was altered by a physical shock due to the initiation of shear-rupture processes involved in the SSE. A similar mechanism was proposed by Husen and Kissling (2001).

In the Tokai area, high-pressure uids are distributed along the subducting plate boundary and are centered around the depth of the Moho $(\sim 30 \mathrm{~km})$ (Kodaira et al., 2004; Kato et al., 2010). At depths shallower than the Moho, the plate boundary forms a low-permeability barrier (Audet et al., 2009). Recent seismic tomography measurements in the Tokai district (Kato et al., 2010) also indicate the presence of an impermeable cap rock covering the subducting plate boundary from above. These observations imply that uids released by the dehydration of the oceanic crust are subjected to increased pressure because they are con ned within a space bordered from above by the overlying barrier and by seals near the upper and lower ends of the slow-slip area along the plate boundary (Fig. 6(a)). The initiation of the SSE may have broken the seals on both ends of the fault fracture zone and released these uids. The liberated uids probably moved primarily within the faultfracture zone along the plate boundary, which is thought to be more permeable than the surrounding crust.

\subsection{Mass redistribution indicated by the observed} gravity changes

The spatial pattern of gravity changes mentioned in Section 2.5 suggests the ascension of mass anomalies along the plate interface. This could be generated if uids owed upward along the fault-fracture zone according to the above mechanism. The decrease in distance between the mass centroid of the uid and the observation sites can explain the increase in gravity to the southeast. Downward ow along the plate boundary is also conceivable, but the gravity data indicate the dominance of upward ow. Fluid ow into the shallower part of the plate interface may have been eas- 
(a)

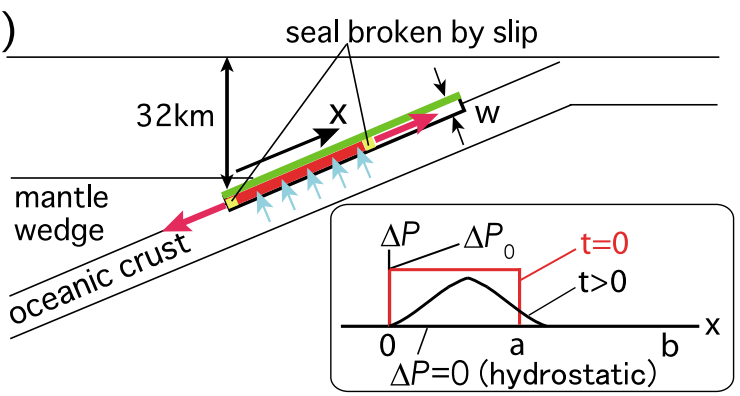

(b)

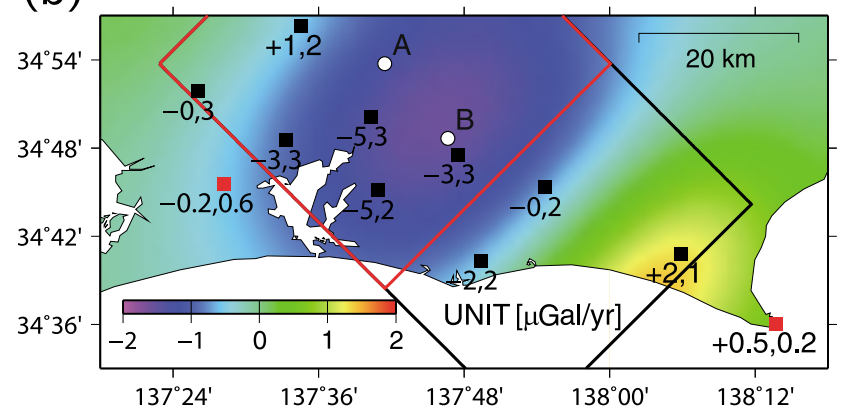

Fig. 6. (a) Vertical cross section of the plate subduction zone and the configuration of the model. $X$ denotes the distance along the plate boundary from the lower end of the zone where high-pressure fluids exist. The dip angle is $15^{\circ}$. The model has a horizontal dimension of $40 \mathrm{~km}$ perpendicular to the page. The bottom right box shows the pressure distribution along the plate interface. (b) Observed and modeled average rates of gravity changes $(\mu \mathrm{Gal} / \mathrm{yr})$. The observed values are indicated in figures, followed by $1 \sigma$ (see also Table 1 ). The color contour illustrates the modeled changes. The red rectangle shows the horizontal projection of the area on the plate boundary initially filled with high-pressure fluids, which is consistent with the high-Poisson-ratio zone indicated by seismic tomography. After rupture was initiated by the slow slip, the fluids spread upward along the plate interface into the area delimited by the black rectangle. The white circle marked as A denotes the center of mass of the high-pressure fluids before the SSE, which moved to B by 2009.

ier because the permeability generally decreases with depth due to the increasing stress and pressure.

\subsection{Mathematical formulation}

We modeled the above fluid flow using a poroelasticity theory based on Darcy's law (Suzuki and Yamashita, 2006). In this theory, fluid flow is described by a diffusion equation that can be derived from Eqs. (11), (12) and (30) in their paper:

$$
\left[\phi / K_{\mathrm{f}}-\phi / K_{\mathrm{s}}\right] \partial p_{\mathrm{f}} / \partial t=(\kappa / \eta) \nabla^{2} p_{\mathrm{f}},
$$

where $\phi, K_{\mathrm{s}}, K_{\mathrm{f}}, p_{\mathrm{f}}, t, \kappa$, and $\eta$ denote the porosity, bulk moduli of the solid and fluid phases, respectively, fluid pressure, time, permeability and fluid-phase viscosity, respectively (Suzuki and Yamashita, 2006). Here, terms associated with dynamic rupture and thermoporoelastic effects were omitted because those terms are negligible on the characteristic time scale of the SSE. Variations over time in the porosity and the Terzaghi effective stress (i.e., equation (15) of Suzuki and Yamashita (2006)) were also ignored because their contributions were small compared to the terms expressed in Eq. (1). Darcy's law was taken into account in deriving the right-hand side. We set the poroelastic parameters at $\phi=0.03$, assuming a pressure of approximately $0.75 \mathrm{GPa}$ and a temperature of approximately $400^{\circ} \mathrm{C}$ in the
Tokai slow-slip area based on results for the subduction zone in southwestern Japan (Hacker et al., 2003; Liu and Rice, 2007); $K_{\mathrm{f}}=3.3 \mathrm{GPa} ; \eta=2.8 \times 10^{-4} \mathrm{~Pa} \mathrm{~s}$ as in Suzuki and Yamashita (2009); $K_{\mathrm{s}}=50 \mathrm{GPa}$.

Figure 6(a) shows the configuration of the model. Highpressure fluids are initially confined between $X=0$ and $a(=40 \mathrm{~km})$. The horizontal projection of this area is shown by the red rectangle in Fig. 6(b). The initial pressure increment, $\Delta P$, was set at $500 \mathrm{MPa}$, which represents an average lithostatic stress at depths of around $25 \mathrm{~km}$, as indicated by previous studies (Kodaira et al., 2004; Kato et al., 2010). At $t=0$, the seals shown in yellow are broken. For $t>0$, the boundary condition $\Delta P=0$ was imposed at $X=0$ and $b$, which means that fluid flow is constrained within the area delimited by the black rectangle in Fig. 6(b). The upper conduits $(a<X<b)$ were added to account for the ascension of the mass centroid. The value of $b(=$ $65 \mathrm{~km}$ ) was determined by trial and error.

In this diffusion model, fluids flow out of the area delimited by the black rectangle when the boundary condition $\Delta P=0$ is imposed. Therefore, the total fluid mass in the area gradually decreases over time. However, at sites to the southeast, the effects of advection were larger than the effects of diffusion, which caused the gravity to increase. When the upper conduits were not added, the gravity increases did not occur at R1 and A1. However, the gravity decreases at the other sites could still be reproduced by slightly modifying the poroelastic parameters and the boundaries of the model.

The associated density changes were derived from equations (15), (19), and (20) of Suzuki and Yamashita (2006):

$$
\begin{aligned}
\partial \rho_{\text {bulk }} / \partial t & =(1-\phi) \partial \rho_{\mathrm{s}} / \partial t+\phi \partial \rho_{\mathrm{f}} / \partial t \\
& =\left[(1-\phi) \rho_{\mathrm{s}} / K_{\mathrm{s}}+\phi \rho_{\mathrm{f}} / K_{\mathrm{f}}\right] \partial p_{\mathrm{f}} / \partial t .
\end{aligned}
$$

Finally, the gravity changes were calculated by integrating the above changes in bulk density over the area delimited by the black rectangle (Fig. 6(b)).

\subsection{Inversion for the fracture-zone width and perme- ability}

The permeability governing the diffusion rate $(\kappa)$ and the effective width of the fluid conduits $(W)$ were determined so that the difference between the modeled and observed gravity changes was minimized. An inversion analysis based on a grid-search algorithm revealed that optimal fit was obtained for $W=500-1000 \mathrm{~m}$ and $\kappa=0.4-4 \times 10^{-15} \mathrm{~m}^{2}$ (Fig. 7). Here,

$$
\chi^{2}=(1 / N) \sum_{i=1, N}\left[\dot{g}_{i}^{\mathrm{MODEL}}-\dot{g}_{i}^{\mathrm{OBS}}\right]^{2} / \sigma_{i}^{2},
$$

where $\dot{g}_{i}$ is the average gravity change rate at the $i$ th station during 2004-2009 (2001-2009 for the reference site A1), $N$ is the total number of observation sites, and $\sigma_{i}$ is the standard deviation of the linear regression against the observations at the $i$ th station (solid lines in Figs. 3 and 4, see also column (e) of Table 1). The trends in modeled gravity changes depended primarily on these two factors, $W$ and $\kappa$. Altering the porosity $\phi$ and the location of the boundary did not affect the gravity change rates by more than one order of magnitude. 


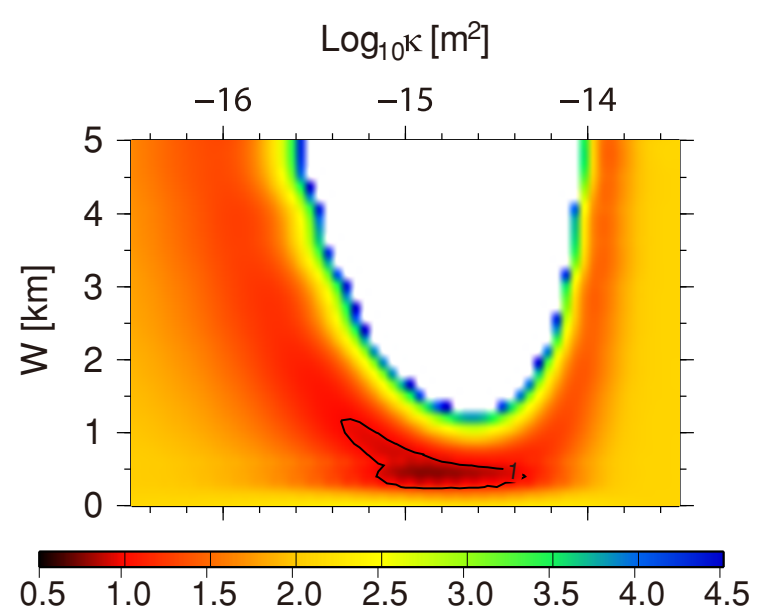

Fig. 7. Distribution of $\chi^{2}$ (Eq. (3)) in the inverse analysis of the gravity change rates. The horizontal and vertical axes denote the permeability $\kappa$ and the width $W$ of the fluid conduits, respectively. Color contours are drawn only in areas where $\chi^{2}<4.5$.

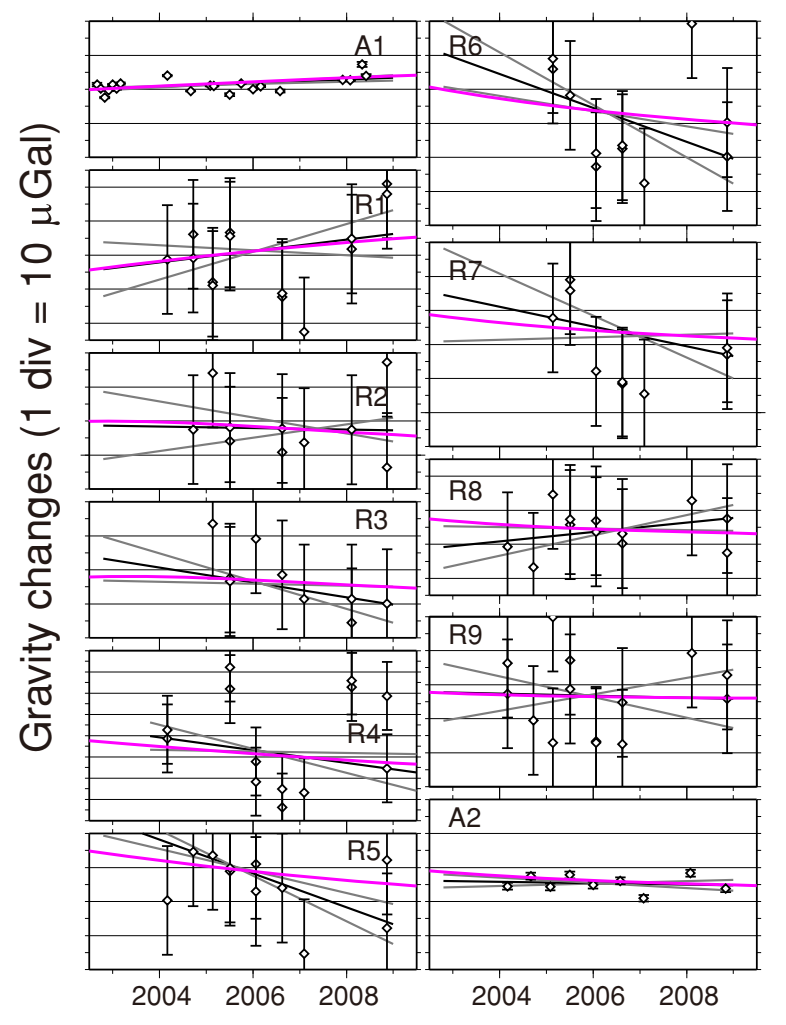

Fig. 8. Comparison of the observed and modeled gravity changes. The black and gray solid lines denote the observed linear trends and their prediction bands. The purple curves denote the modeled gravity changes. Circles with error bars are the individual records of relative measurements (same as in Fig. 4).

The modeled gravity changes for $W=500 \mathrm{~m}$ and $\kappa=10^{-15} \mathrm{~m}^{2}$ are shown superimposed on Fig. 6(b) and Fig. 8. These parameter values gave the best fit to the observed data. The fit is very close, except at R6 and R7, where the modeled gravity changes are somewhat smaller than the observed ones. When the model was adjusted to improve the fit at these sites, the modeled changes became too large at A1 and A2. The parameter values cited above

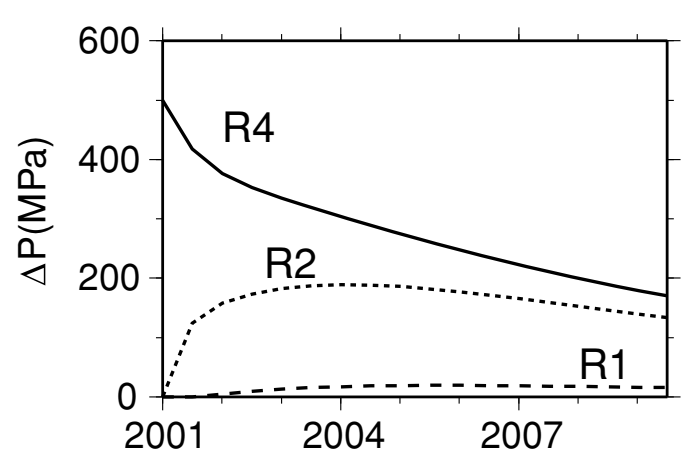

Fig. 9. Time variations in the modeled pressure increments at selected sites on the plate boundary, located beneath R1, R2, and R4. $\Delta P=0$ corresponds to the hydrostatic pressure.

were preferred because we assigned greater weights to the absolute gravity measurements. Figure 9 shows time variations in the modeled pressure increments. The ascension of the mass centroid of the fluids increases the pressure beneath R1 and R2 during earlier periods, but the fluids later begin to leak out of the area, and the pressure increment approaches zero. Beneath R4, the pressure follows a monotonous decline. According to the model, the mass centroid ascends along the interface by $2.6 \mathrm{~km}$ in terms of depth (Fig. 6(b)), and $10^{11} \mathrm{~kg}$ worth of fluid mass flows out of the modeled area (the black rectangle in Fig. 6(b)).

\section{Discussion and Conclusions}

In the model presented here, we assumed a lithostatic pressure before the occurrence of the SSE. However, the model could hardly explain the observed gravity data when the initial pressure increment was more than one order of magnitude smaller than the lithostatic value (i.e., when $\Delta P<50 \mathrm{MPa}$ ). In this case, either the fluid volume had to be larger or a higher permeability had to be assumed. The former possibility is restricted by the assumption that fluids are present only within the fault-fracture zone in the slowslip area. When the latter was assumed, the time-scale of diffusion became smaller than the duration of the SSE, and the pressure reached equilibrium soon after the initiation of the SSE, resulting in poorer agreement between the model and the observations.

Husen and Kissling (2001) modeled post-seismic fluid flow due to a large subduction earthquake in Chile. They proposed that the low-permeability barrier was ruptured by the event and that fluids flowed out into the overlying continental plate. For the present SSE, the observed gravity changes did not indicate rupture of the barrier because vertical fluid conduits would have increased surface gravity throughout the slow-slip area.

The estimated permeability can be compared to that of oceanic plates at depths where SSEs occur. Sibson and Rowland (2003), who considered variations in the stress state due to fluid overpressuring, stated that the permeability of the subduction zone in New Zealand was less than $10^{-17} \mathrm{~m}^{2}$. Spinelli and Wang (2009), who used surface heat-flux data, determined that the upper limit on the permeability along the Nankai margin in Japan was $10^{-10} \mathrm{~m}^{2}$. A numerical simulation of dynamic rupture growth induced 
by slow slip revealed that SSEs did not easily occur when the permeability of a fault zone was less than $10^{-18} \mathrm{~m}^{2}$ (Suzuki and Yamashita, 2009). Because permeability can vary by many orders of magnitude due to small differences in uid pathways and composition, our estimate can be regarded as lying within a reasonable range. The faultfracture-zone width of $500 \mathrm{~m}$ is consistent with a scaling relationship between fault-process-zone width and fault length for strike-slip faults (Vermilye and Scholz, 1998), although no similar relationship has previously been reported for subduction zones.

We therefore conclude that the observed gravity changes were possibly due to the migration of high-pressure uids along the fracture zone during the SSE. This conclusion also implies that the uids may have lubricated the plate interface and thus promoted the shear-rupture process of the SSE.

In our model of the Tokai SSE, the maximum pressure loss by 2009 in the slip area is about $300 \mathrm{MPa}$ (Fig. 9). It is therefore suggested that variations of that magnitude may have taken place in uid pressures during the longterm SSE. Geodetic survey results (Yamamoto et al., 2005) indicate that at least three SSEs of different magnitudes have taken place in the Tokai region during the past 27 years since 1983, including the event studied here. We expect that before the next SSE begins, uid pressures will return to a lithostatic level, reversing the trends of gravity changes due to the recovery of the seals. The temporal variability of uid pressures within a fault zone during the seismic cycle is supported by a geological model describing fault-valve behavior (Sibson, 1992). The evaluation of the recovery and the decreasing rates of uid pressure using real observations is interesting because these rates may govern the uctuating recurrence periods of the Tokai SSEs.

Gravity changes on the order of $1-10 \mu \mathrm{Gal}$ should be expected in the slow-slip area during the next SSE if the event magnitude and the permeability of the plate boundary remain the same. In that case, if the accuracy of gravity measurements improves to the $1-\mu \mathrm{Gal} / \mathrm{yr}$ level, it should be possible to clearly detect uid ow as described above. If the permeability falls below $10^{-15} \mathrm{~m}^{2}$, however, it may be dif cult to detect uid ow due to the proposed mechanism. The use of superconducting gravimeters and rigorous corrections for groundwater disturbances must be considered.

The Meteorological Research Institute (2009) points out that deep low-frequency tremor activity increased between 2000 and 2005 along the plate boundary, at depths around $30 \mathrm{~km}$, on the northern side of the area of maximum slow slip. The mechanism of the change in activity has not been revealed. Using our model, we speculate that leakage of high-pressure uids toward deeper portions increased poreuid pressures there to cause tremors. The Institute also reports that the change in activity may have begun in 1999 prior to the SSE. Our model cannot interpret this phenomenon because no gravity observations were in operation in the slow-slip area before the 2000 Tokai SSE. To help reveal its mechanism, it would be useful to nd out if gravity changes are going to be observed, prior to a future SSE, synchronously with a change in tremor activity.

Gravity increase was seen only at two stations lying the farthest to the east. In this respect, the results of previous surveys (Kusumoto et al., 2008) could be used in partial support of this spatial pattern. These researchers reported a long-term gravity increase near the tip of the peninsula using relative observation data obtained in 1970 and 2007. The gravity increase averaged over the peninsula was about $30 \mu \mathrm{Gal}$ with respect to a site located near W3, and the increase was the largest near R1. The effects of crustal movement were removed by Bouguer correction. In our model, the gravity change was nearly zero at $\mathrm{W} 3$, and the location of the maximum increase almost agreed with their result (Fig. 6(b)). Three consecutive SSEs occurring at 10-year intervals, with each event continuing over the full 10-year cycle, are expected to bring about a total gravity change of about $30 \mu \mathrm{Gal}$. This estimate is in rough agreement with the results of Kusumoto et al. (2008) and Yamamoto et al. (2005). Therefore, the long-term gravity changes observed by Kusumoto et al. (2008) may be associated with uid migrations caused by SSEs. In 2008, we established a new absolute gravity measurement site between stations W2 and W3. It is important to determine whether upward migration of high-pressure uids really happens because upward uid ow could weaken the effective normal stress in the seismogenic zone.

Acknowledgments. We have been able to conduct the gravity observations by courtesy of Drs. Tsuneo Yamaguchi, Toshiki Watanabe of Nagoya University and Ryoya Ikuta of Shizuoka University. We used the F3 solution of the Geospatial Information Authority of Japan for the GPS data. We thank Drs. Yasuko Takei, Teruo Yamashita, and Kevin Fleming for reviewing an early version of the manuscript. We also thank Dr. John Townend and an anonymous reviewer for valuable comments which helped to improve the paper signi cantly.

\section{References}

Audet, P., M. G. Bostock, N. I. Christensen, and S. M. Peacock, Seismic evidence for overpressured subducted oceanic crust and megathrust fault sealing, Nature, 457, 76-78, 2009.

Battaglia, M., C. Roberts, and P. Segall, Magma intrusion beneath Long Valley caldera con rmed by temporal changes in gravity, Science, $\mathbf{2 8 5}$, 2119-2122, 1999.

Central Disaster Management Council, Cabinet Of ce, Government of Japan, Committee Report on the Tokai Earthquake, 2001 (in Japanese). Chen, J. L., C. R. Wilson, B. D. Tapley, and S. Grand, GRACE detects coseismic and postseismic deformation from the Sumatra-Andaman earthquake, Geophys. Res. Lett., 34, L13302, doi:10.1029/2007GL030356, 2007.

Delahaye, E. J., J. Townend, M. E. Reyners, and G. Rogers, Microseismicity but no tremor accompanying slow slip in the Hikurangi subduction zone, New Zealand, Earth Planet. Sci. Lett., 277, 21-28, 2009.

Furuya, M., S. Okubo, W. Sun, Y. Tanaka, J. Oikawa, H. Watanabe, and T. Maekawa, Spatiotemporal gravity changes at Miyakejima Volcano, Japan: Caldera collapse, explosive eruptions and magma movement, $J$. Geophys. Res., 108, 2219-2235, 2003.

Geological Survey of Japan, The variation of the groundwater level, discharge rate, tilt meter and three components strain in the Tokai District and Izu Peninsula, Central Japan. (from Nov. 2001 to Apr. 2002) (25), Rep. Coord. Comm. Earthq. Predict., 68, 355-365, 2002.

Geological Survey of Japan, The variation of the groundwater level, discharge rate, tilt meter and three components strain in the Tokai District and Izu Peninsula, Central Japan. (from Nov. 2002 to Apr. 2003) (27), Rep. Coord. Comm. Earthq. Predict., 70, 331-342, 2003.

Geological Survey of Japan, The variation of the groundwater level, discharge rate tilt meter, three components strain, subsidence, and radon concentration in the Tokai District and Izu Peninsula, Central Japan. (from Nov. 2003 to Apr. 2004) (29), Rep. Coord. Comm. Earthq. Predict., 72, 455-468, 2004. 
Geological Survey of Japan, The variation of the groundwater level, discharge rate, tilt meter, three components strain, and subsidence in the Tokai, Kanto District and lzu Peninsula, Central Japan. (from Nov. 2005 to Apr. 2006)(33), Rep. Coord. Comm. Earthq. Predict., 76, 413-445, 2006.

Geological Survey of Japan, The variation of the groundwater level, discharge rate, tilt meter, three-component strain, and subsidence in the Tokai, Kanto District and Izu Peninsula, Central Japan. (from May 2008 to Oct. 2008) (36), Rep. Coord. Comm. Earthq. Predict., 81, 467-482, 2009.

Geological Survey of Japan, The variation of the groundwater level, discharge rate, tilt meter, three-component strain, and subsidence in the Tokai, Kanto District and Izu Peninsula, Japan. (from May 2009 to Oct. 2009) (40), Rep. Coord. Comm. Earthq. Predict., 83, 370-382, 2010.

Geospatial Information Authority of Japan, Crustal movements in the Tokai District, Rep. Coord. Comm. Earthq. Predict., 82, 294-309, 2009a.

Geospatial Information Authority of Japan, Crustal movements in the Tokai District, Rep. Coord. Comm. Earthq. Predict., 81, 438-439, 2009b.

Geospatial Information Authority of Japan, Crustal movements in the Tokai District, Rep. Coord. Comm. Earthq. Predict., 82, 27, 2009c.

Hacker, B. R., G. A. Abers, and S. M. Peacock, Subduction factory, 1, Theoretical mineralogy, densities, seismic wave speeds, and $\mathrm{H}_{2} \mathrm{O}$ contents, J. Geophys. Res., 108(B1), 2029, doi:10.1029/2001JB001127, 2003.

Husen, S. and E. Kissling, Postseismic uid ow after the large subduction earthquake of Antofagasta, Chile, Geology, 29, 847-850, 2001.

Imanishi, Y., T. Sato, T. Higashi, W. Sun, and S. Okubo, A network of superconducting gravimeters detects submicrogal coseismic gravity changes, Science, 306, 476-478, 2004.

Jónsson, S., P. Segall, R. Pedersen, and G. Björnsson, Post-earthquake ground movements correlated to pore-pressure transients, Nature, $\mathbf{4 2 4}$, 179-183, 2003

Kato, A., M. Ohnaka, and H. Mochizuki, Constitutive properties for the shear failure of intact granite in seismogenic environments, J. Geophys. Res., 108(B1), 2060, doi:10.1029/2001JB000791, 2003.

Kato, A., T. Iidaka, R. Ikuta, Y. Yoshida, K. Katsumata, T. Iwasaki, S. Sakai, C. Thurber, N. Tsumura, K. Yamaoka, T. Watanabe, T. Kunitomo, F. Yamazaki, M. Okubo, S. Suzuki, and N. Hirata, Variations of uid pressure within the subducting oceanic crust and slow earthquakes, Geophys. Res. Lett., 37, L14310, doi:10.1029/2010GL043723, 2010.

Kato, T. and K. Tsumura, Vertical land movement in Japan as deduced from tidal record (1951-1978), Bull. Earthq. Res. Inst., 54, 559-628, 1979 (in Japanese)

Kazama, T. and S. Okubo, Hydrological modeling of groundwater disturbances to observed gravity: Theory and application to Asama Volcano, Central Japan, J. Geophys. Res., 114, B08402, doi:10.1029/2009JB006391, 2009.

Kazama, T., Hydrological modeling of groundwater disturbances to observed gravity data toward high-accuracy monitoring of magma transfer in volcanoes, Doctoral Thesis, Univ. of Tokyo, 2010.

Kodaira, S., T. Iidaka, A. Kato, J.-O. Park, T. Iwasaki, and Y. Kaneda, High pore uid pressure may cause silent slip in the Nankai Trough, Science, 304(5675), 1295-1298, 2004

Kusumoto, S., T. Sakai, T. Nagao, M. Satomura, W. Sun, and S. Okubo, Precise gravity measurements around the Omaezaki peninsula, Shizuoka, Japan, for nding the interseismic and coseismic gravity changes, J. School Mar. Sci. Technol. Tokai Univ., 6(3), 1-9, 2008 (in Japanese with English abstract).

Liu, Y. and J. R. Rice, Spontaneous and triggered aseismic deformation transients in a subduction fault model, J. Geophys. Res., 112, B09404, doi:10.1029/2007JB004930, 2007.

Matsumoto, K., T. Sato, T. Takanezawa, and M. Ooe, GOTIC2: A program for computation of oceanic tidal loading effect, J. Geod. Soc. Jpn., 47, 243-248, 2001

Mazzotti, S., A. Lambert, N. Courtier, L. Nykolaishen, and H. Dragert, Crustal uplift and sea level rise in northern Cascadia from GPS, absolute gravity, and tide gauge data, Geophys. Res. Lett., 34, L15306, doi:10.1029/2007GL030283, 2007.

Menke, W., Geophysical Data Analysis: Discrete Inverse Theory, Revised Edition, 289 pp., Academic Press, Inc., New York, 1989.

Meteorological Research Institute, Japan Meteorological Agency, Deep low-frequency tremor activity change prior to slow-slip events, Rep. Coord. Comm. Earthq. Predict., 82, 486-490, 2009 (in Japanese).
Miyazaki, S., P. Segall, J. J. McGuire, T. Kato, and Y. Hatanaka, Spatial and temporal evolution of stress and slip rate during the 2000 Tokai slow earthquake, J. Geophys. Res., 111, B03409, doi:10.1029/2004JB003426, 2006.

Miyazawa, M. and J. Mori, Evidence suggesting uid ow beneath Japan due to periodic seismic triggering from the 2004 Sumatra-Andaman earthquake, Geophys. Res. Lett., 33, L05303, doi:10.1029/2005GL025087, 2006.

Mouyen, M., F. Masson, C. Hwang, C.-C. Cheng, R. Cattin, C. W. Lee, N. Le Moigne, J. Hinderer, J. Malavieille, R. Bayer, and B. Luck, Expected temporal absolute gravity change across the Taiwanese Orogen, a modeling approach, J. Geodyn., 48, 284-291, 2009.

Nakamura, M., H. Watanabe, T. Konomi, S. Kimura, and K. Miura, Characteristic activities of subcrustal earthquakes along the Outer Zone of Southwestern Japan, Ann. Disas. Prev. Res. Inst. Kyoto Univ., 40(B-1), 1997 (in Japanese with English abstract).

Noguchi, S., Geometry of the Philippine Sea Slab and the convergent tectonics in the Tokai District, Japan, J. Seismol. Soc. Jpn., 49, 295325, 1996 (in Japanese with English abstract).

Ogawa, R. and K. Heki, Slow postseismic recovery of geoid depression formed by the 2004 Sumatra-Andaman Earthquake by mantle water diffusion, Geophys. Res. Lett., 34, L06313, doi:10.1029/2007GL029340, 2007.

Okubo, S., Gravity and potential changes due to shear and tensile faults in a half-space, J. Geophys. Res., 97(B5), 7137-7144, 1992.

Okubo, S., S. Yoshida, T. Sato, Y. Tamura, and Y. Imanishi, Verifying the precision of a new generation absolute gravimeter FG5-Comparison with superconducting gravimeters and detection of oceanic loading tide, Geophys. Res. Lett., 24(4), 489-492, 1997.

Scholz, C. H., Earthquakes and friction laws, Nature, 391(6662), 37-42, 1998.

Schwartz, S. Y. and J. M. Rokosky, Slow slip events and seismic tremor at circum-Paci c subduction zones, Rev. Geophys., 45, RG3004, doi:10.1029/2006RG000208, 2007.

Sibson, R. H., Implications of fault-valve behaviour for rupture nucleation and recurrence, Tectonophysics, 211, 283-293, 1992.

Sibson, R. H. and J. V. Rowland, Stress, uid pressure and structural permeability in seismogenic crust, North Island, New Zealand, Geophys. J. Int., 154, 584-594, 2003.

Song, T.-R. A., D. V. Helmberger, M. R. Brudzinski, R. W. Clayton, P. Davis, X. Pérez-Campos, and S. K. Singh, Subducting slab ultra-slow velocity layer coincident with silent earthquakes in southern Mexico, Science, 324, 502-506, 2009.

Spinelli, G. A. and K. Wang, Links between uid circulation, temperature, and metamorphism in subducting slabs, Geophys. Res. Lett., 36, L13302, doi:10.1029/2009GL038706, 2009.

Suzuki, T. and T. Yamashita, Nonlinear thermoporoelastic effects on dynamic earthquake rupture, J. Geophys. Res., 111, B03307, doi:10.1029/2005JB003810, 2006.

Suzuki, T. and T. Yamashita, Dynamic modeling of slow earthquakes based on thermoporoelastic effects and inelastic generation of pores, J. Geophys. Res., 114, B00A04, doi:10.1029/2008JB006042, 2009.

Tanaka, Y., S. Okubo, M. Machida, I. Kimura, and T. Kosuge, First detection of absolute gravity change caused by earthquake, Geophys. Res. Lett., 28(15), 2979-2981, 2001.

Torge, W., Gravimetry, 465 pp, Walter de Gruyter, Berlin, New York, 1989. Van Camp, M., S. D. P. Williams, and O. Francis, Uncertainty of absolute gravity measurements, J. Geophys. Res., 110, B05406, doi:10.1029/2004JB003497, 2005.

Vermilye, J. M. and C. H. Scholz, The process zone: A microstructural view of fault growth, J. Geophys. Res., 103, 12,223-12,237, 1998.

Vidale, J. E., A. Ghosh, J. R. Sweet, K. C. Creager, A. Wech, and H. Houston, Streaking tremor in Cascadia, Eos Trans. AGU, 90(52), Fall Meet. Suppl., Abstract T21F-07, 2009.

Yamamoto, E., S. Matsumura, and T. Ohkubo, A slow slip event in the Tokai area detected by tilt and seismic observation and its possible recurrence, Earth Planets Space, 57, 917-923, 2005.

Y. Tanaka (e-mail: y-tanaka@eri.u-tokyo.ac.jp), A. Kato, T. Sugano, G. Fu, X. Zhang, M. Furuya, W. Sun, S. Okubo, S. Matsumoto, M. Honda, Y. Sugawara, I. Ueda, M. Kusaka, and M. Ishihara 